\title{
DO I KNOW THE PATH AHEAD (LOOKING AT THE THOUGHTS OF A PRETERM INFANT
} AFTER DISCHARGE)

\author{
S. Job ${ }^{1}$, D.V. Karuppaswamy ${ }^{2}$ \\ ${ }^{1}$ Paediatrics and Neonates, NHS, ${ }^{2}$ Paediatrics and Neonates, Colchester University Hospital Foundation \\ Trust, Colchester, UK
}

Aim: This Audit was done to assess existing local and national practice in the follow-up of newborns at risk (less than 32weeks gestation and or under 1500grams birth weight).

Data collection: 202 questionnaires were sent to neonatal units across the United Kingdom and the response was collected.

Results: 108 units responded, of which 88 (81\%) were district general and 20 (19\%) were tertiary hospitals. $70(65 \%)$ units had a local guideline for follow up, where as 38(35\%) didn't. $59(50 \%)$ hospitals reviewed them at six weeks for the first follow up and second between 3-6 months in 43 (40\%) hospitals. Subsequent follow up was at 6 months in $32(29 \%)$ and 12 months in $38(35 \%)$ hospitals. Most units 76 ( 70\%) discharged around two years of age. Consultants conducted these clinics $107(99 \%)$ and $76(70 \%)$ had follow up with other teams like physiotherapy 46 (42.5\%) and occupational therapy 55 (50.9\%).

An assessment tool was used in 82 (75.9\%) hospitals which included Bayley $22(20 \%)$ and Griffiths 26 (24\%).These assessments were performed by consultants/ trainees in $68(63 \%)$, the community support team in $21(19 \%)$ hospitals. The timing varied between land 2 years of age with the majority being at 2 years, 26 $(24 \%)$.

Conclusion: Individual units have own practices utilising their resources . Evidence that if these children are identified and supported early, the impact on the long term development of these infants will be minimised. We therefore recommend a national guideline. 